\title{
Assessment of Synergy Degree among Process of Integrated Municipal Solid Waste Management in Harbin, China
}

\author{
Wenna Wang ${ }^{1}$, Zhujie Chu ${ }^{2,3 *}$, An Zhou ${ }^{1}$, Tianyue Zhang ${ }^{1}$ \\ ${ }^{1}$ School of Economics and Management, Harbin Engineering University, \\ Harbin 150001, China; No. 145 Nantong Street, Nangang District, Harbin, China \\ ${ }^{2}$ School of International and Public Affairs, Shanghai Jiao Tong University, \\ Shanghai 200240, China; No. 800 Dongchuan RD, Minhang District, Shanghai, China \\ ${ }^{3}$ China Institute for Urban Governance, Shanghai Jiao Tong University, \\ Shanghai 200240, China; No. 800 Dongchuan RD, Minhang District, Shanghai, China
}

Received: 8 June 2021

Accepted: 30 August 2021

\begin{abstract}
Integrated Municipal Solid Waste (MSW) management is the foundation step for improving the efficiency of MSW management and satisfying the urban environment sustainability requirements. Therefore, this study aims to identity the weakness in the process of integrated MSW management, and support approaches to an effective integrated MSW management according to practice of the city governance. In this paper, the MSW management synergy system with four subsystems (MSW separation, MSW collection, MSW transportation, and MSW disposal) has been constructed in Harbin, China. Synergy degree model is used to calculate the order degrees of the subsystems and the synergy system from 2010 to 2019, and then study the synergistic development and orderly evolution trend of MSW management. The results indicate that the order degrees of the subsystems all develop to an ordered state, and the order degree of the MSW transportation subsystem of integrated MSW management synergy system in the study area improved continuously. Meanwhile, the order degree of the MSW separation subsystem developed slowly, staying at a relatively low level overall, indicating that MSW separation should be paid close attention to in Harbin.
\end{abstract}

Keywords: municipal solid waste, management process, synergy degree assessment, sustainable development

e-mail: chuzhujie@126.com 


\section{Introduction}

Nowadays, the rapid growth in the population and urbanization have led to environmental pollution and a drastic rise in municipal solid waste (MSW) generation [1], and has become a major environment quality and public health concern in recent years [2-3]. In 2019, MSW generated 242.06 million tons in China, however, there were still 1.93 million tons of MSW had not been properly harmless treated in this year [4]. This issue has brought heavy pressure on the environment quality and sustainable development [5-6]. Integrated MSW management is recognized as the contemporary and systematic approach to MSW management in a sanitary and environmentally friendly manner [7]. Thus, it is necessary to focus on the integrated MSW management, which will enhance the basis for the effectiveness of MSW management.

A number of studies have shed light on MSW management which is an increasingly complicated process involving various contributing factors [8]. MSW management includes activities related to the generation, classification, collection, transportation, and disposal of MSW [9]. Sharholy et al. [10] claimed that efficient MSW management requires support from both the authorities and citizens, with evolving community awareness and societal interest. Guerrero et al. [11] showed that an effective MSW management system should recognize environmental, sociocultural, and economic bonds to facilitate effective MSW management, and they also claimed that decisionmakers should be required to report upon the situation in cities and make positive alterations, developing integrated MSW management strategies adjusted to citizens' demands. Tan et al. [12] claimed that a sustainable MSW management system needs to consider not only economic factors but also multiple environmental and social criteria to prevent harmful effects on the environment and human health. Fernando [13] identified problems and challenges faced in the implementation of MSW management. Zaman [14] analyzed MSW management performance and made comparisons between municipalities or technologies to support decisions that deliver beneficial environmental, social, economic, and political impacts in practice. Paes et al. [15] analyzed a MSW management system that integrated environmental and economic indicators, which considers the total social costs, operating and investments costs of environmental externalities, to improve the current MSW management system.

Besides, many studies have focused on the multidimensional systemic approach to MSW sustainable management in the recent years. The most widely used decision support frameworks in the field of MSW sustainable management are life cycle assessment (LCA) and multi-criteria decision making (MCDM). For LCA, it is a system analysis tool to evaluate the total environmental impacts of MSW management options in strategy-planning and decision-making processes
[16], and it has been widely used to provide preferable environmental outcomes through MSW management strategies [17]. Rigamonti et al. [18] applied a LCA model to evaluate the impacts associated with different sub-units that compose a MSW management system. For MCDM, it has become an important and convenient supporting tool for MSW management because it can handle problems involving multiple dimensions and conflicting criteria [19]. Frequently used MCDM tools include AHP (analytical hierarchy process), MOMILP (multi-objective mixed-integer linear programming), TOPSIS (technique for order preference with similarity to ideal solution) and other forms of LP (linear programming). For example, Parekh et al. [20] demonstrated the application of AHP to assign the weightage of each performance indicator for MSW management. Harijani et al. [21] proposed a MOMILP model to design the MSW management network, considering the economic, environmental and social dimensions of sustainability. Su et al. [22] evaluated the performance of MSW management policies in Taoyuan County (Taiwan) with respect to social, economic and management criteria by the approach of TOPSIS. Paul et al. [23] introduced a LP model for MSW management to optimize the allocation of MSW to existing treatment facilities.

Integrated MSW management systems provide solutions through systematic investigation of demands which handles the problem from different points [24]. Integrated MSW management is a contemporary and systematic approach to MSW management in a sanitary and environmentally friendly manner [25]. Dong et al. [26] showed that integrated MSW management facilities implementation could reduce the MSW and emissions. It is an approach for minimizing MSW generation and maximizing recycling without harming human health or environment to meet sustainable economic, environmental and social needs [27-28] by the application of proper methods and management programs [29]. Tsai et al. [30] claimed that the integrated MSW management approach seeks to create administrative strategies for efficient MSW management and sustainability. Marshall and Farahbakhsh [31] also stated that an integrated MSW management aims to establish an efficient MSW management system by incorporating and integrating the interrelated processes along the entire MSW management chain. As a result, integrated MSW management is an increasingly complicated process involving various contributing factors, it is complex because a sustainable MSW management system needs to consider not only economic factors but also multiple environmental and social criteria to prevent short and long-term harmful effects on the environment and human health [32]. Integrated MSW management has been proposed as the top solution for least environmental impacts and enhanced recovery of resources from MSW [33-34].

The integration among different phases of MSW management (separation, collection, transportation, and 
disposal) is paramount. In coordination with sustainable development, this study aims to determine the weakness in the process of integrated MSW management and then provide theoretical support and rational decision-making references for the integrated MSW management combining with the region characteristics. Harbin is located in the severe cold region in northeast China, and it is characterized by severely cold winters lasting nearly half of the year [35]. Its unique cold weather not only leads to the limitations and challenges among MSW collection-transportation-treatment process, resulting in the ineffective MSW management, but also leads to the high overall operation costs of MSW management system. Therefore, developing an integrated MSW management system in Harbin is crucial for protecting resources, the environment, and public health. In this paper, an integrated MSW management synergy system in Harbin consisting of four subsystems (MSW separation subsystem, MSW collection subsystem, MSW transportation subsystem, and MSW disposal subsystem) is constructed from the perspective of whole life cycle theory. Besides, the synergy degree model was used to analyze the order degree value changes of the four subsystems and the synergy degree value changes of the synergy system by different MSW management processes, so as to scientifically reflect the systematic characteristics and development status in the process of integrated MSW management.

\section{Material and Methods}

\section{Study Area}

Harbin, the capital city of Heilongjiang province, is the economic and cultural center in northeastern China, and endowed with abundant natural resources such as forests, minerals, etc. In comparison with other Chinese regions, Harbin faces unique challenges in MSW management systems because of the extreme conditions in which it operates. Harbin experiences cold winters (hit an average of $-30^{\circ} \mathrm{C}$ ) for up to 5 months of the year, its distinctive climate and extreme cold winter permanently freezes the exposed MSW before getting timely collected, increasing the difficulties during the follow-up MSW transportation and treatment process. The frozen ground also increases the skidding risk of MSW transport vehicles in winter. Besides, the typical low ambient temperatures maximize heat loss and restrict microbial activity, negatively affecting treatment effectiveness of MSW incineration and compost stabilization. In addition, the population density in Harbin is lower than certain other Chinese regions, causing the longer MSW transportation distance and higher transportation costs. The combination of the conditions listed above distinguishes Harbin areas from other parts of southerly China. Due to the fact that the cost of MSW collection and transportation accounts for $60 \%-80 \%$ of the total MSW management system costs [36], these situations result in high overall operation costs of MSW management system, and even result in the risk of ineffective of MSW management. The selected study area (Fig. 1) is five districts in Harbin, namely Nan-gang District, Dao-li District, Dao-wai District, Xiang-fang District and Ping-fang District.

\section{Order Parameters}

According to synergy theory, variables that determine the system are called order parameters. The order parameter will in turn dominates the behavior of each subsystem and reflect the evolutionary trend of subsystems and synergy system. Based on the whole life cycle theory, the proper order parameters were selected from four dimensions of MSW management (Table 1), and then an integrated MSW management synergy degree measurement system was constructed.

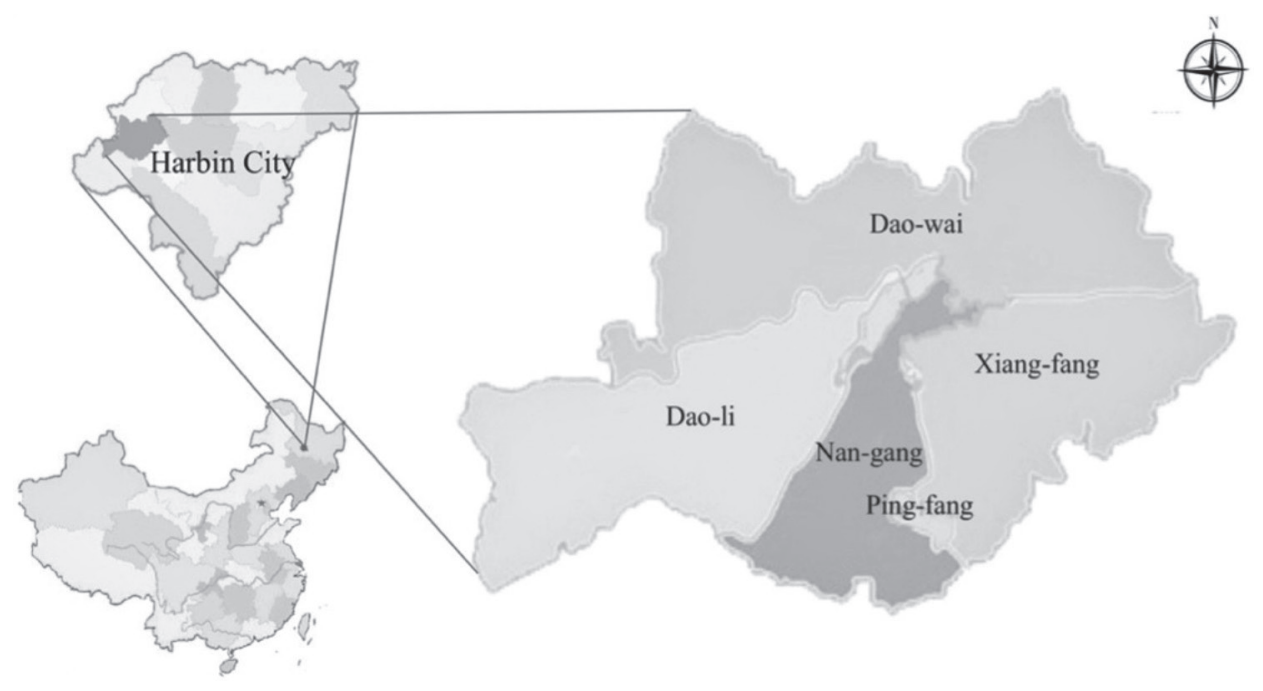

Fig. 1. Study area. 
Table 1. Integrated MSW management order parameter system.

\begin{tabular}{|c|c|c|}
\hline System & Subsystem & Order parameters \\
\hline \multirow{15}{*}{$\begin{array}{l}\text { Integrated MSW } \\
\text { management synergy } \\
\text { system }\end{array}$} & \multirow{4}{*}{$\begin{array}{l}\text { MSW separation subsystem } \\
\qquad\left(X_{1}\right)\end{array}$} & Publicity and education $\left(X_{11}\right)$ \\
\hline & & Public participation $\left(X_{12}\right)$ \\
\hline & & Mandatory policies and regulations $\left(X_{13}\right)$ \\
\hline & & Public MSW separation knowledge $\left(X_{14}\right)$ \\
\hline & \multirow{4}{*}{$\begin{array}{l}\text { MSW collection subsystem } \\
\qquad\left(X_{2}\right)\end{array}$} & MSW collection frequency $\left(X_{21}\right)$ \\
\hline & & Number of MSW containers $\left(X_{22}\right)$ \\
\hline & & Quantity of MSW collection $\left(X_{23}\right)$ \\
\hline & & MSW collection area $\left(X_{24}\right)$ \\
\hline & \multirow{3}{*}{$\begin{array}{l}\text { MSW transportation subsystem } \\
\qquad\left(X_{3}\right)\end{array}$} & Number of special MSW vehicles and equipment $\left(X_{31}\right)$ \\
\hline & & Reasonability of transport times $\left(X_{32}\right)$ \\
\hline & & Reasonability of transport routes $\left(X_{33}\right)$ \\
\hline & \multirow{4}{*}{$\begin{array}{l}\text { MSW disposal subsystem } \\
\left(X_{4}\right)\end{array}$} & Quantity of MSW disposal $\left(X_{41}\right)$ \\
\hline & & MSW disposal technology $\left(X_{42}\right)$ \\
\hline & & MSW reduction performance $\left(X_{43}\right)$ \\
\hline & & MSW recycling performance $\left(X_{44}\right)$ \\
\hline
\end{tabular}

These four subsystems affect and interact with each other, and their interactions influence the evolution of the entire integrated MSW management system. The coordinated development of the four subsystems will help to keep the entire system in an ordered and stable state, promote MSW management efficiency, and boost the environment sustainable development.

\section{Synergy Degree Model}

The synergy degree model can reflect the comprehensive development level of the integrated MSW management synergy system in the study area. Synergy degree is used to measure the degree of coordination and collaboration between the subsystems within integrated MSW management synergy system, which can be reflected by order degrees of order parameters in each subsystem.

It is assumed that the integrated MSW management synergy system consists of four subsystems, $X=\left\{X_{1}, X_{2}, X_{3}, X_{4}\right\}$, that is, the MSW separation subsystem $\left(X_{1}\right)$, MSW collection subsystem $\left(X_{2}\right)$, MSW transportation subsystem $\left(X_{3}\right)$, and MSW disposal subsystem $\left(X_{4}\right)$.

The order parameters for subsystem $X_{i}(i=1,2,3,4)$ are defined as $X_{i}=\left\{X_{i 1}, X_{i 2}, \ldots, X_{i n}\right\}, n \geq 1, \beta_{i j} \leq X_{i j} \leq \alpha_{i j}$, $j \in[1, n]$, with $\alpha_{i j}$ and $\beta_{i j}$ being the upper and lower limits of $X_{i j}$ at the critical system stability point. In general, there are two kinds of order parameters: positive index refers to the order degree of the system increases along with the change of the order parameter and its component value; and the negative index refers to the order degree of system decreases accordingly.
Therefore, the order degree for the order parameters of the subsystem $u_{i}\left(X_{i j}\right)$ can be expressed as:

$$
u_{i}\left(X_{i j}\right)= \begin{cases}\frac{X_{i j}-\beta_{i j}}{\alpha_{i j}-\beta_{i j}}, & j \in[1, k] \\ \frac{\alpha_{i j}-X_{i j}}{\alpha_{i j}-\beta_{i j}}, & j \in[k+1, m]\end{cases}
$$

It can be known that the order degree of the order parameter of the subsystem $u_{i}\left(X_{i j}\right) \in[0,1]$, and the larger $u_{i}\left(X_{i j}\right)$ value is, the more order parameter contributes to the order degree of the subsystem will be. In addition, the total contribution of each order parameter to the subsystem also related to each weight of order parameter. The linear weighting method is used in this paper to integrate the order degree of subsystem, namely:

$$
u_{i}\left(X_{i}\right)=\sum_{j=1}^{n} \omega_{j} u_{i}\left(X_{i j}\right), \quad 0 \leq \omega_{j} \leq 1, \quad \sum_{j=1}^{n} \omega_{j}=1
$$

From Equation (2), $u_{i}\left(X_{i}\right) \in[0,1]$, and the higher the $u_{i}\left(X_{i}\right)$ value is, the higher the order degree of subsystem $x_{i}$ will be. Among them, the weight coefficient $\omega_{j}$ indicates the influence of the order parameter $x_{i j}$ in the orderly operation of the subsystem. To make the results more objective and avoid subjective preferences, entropy weight method can be used to calculate the order parameters weights, which is expressed as follows:

We can first obtain the standardized matrix $R=\left(\gamma_{i j}\right)_{t \times n}, \gamma_{i j} \in[0,1]$, according to Equation (1), where 
rower $t$ is for the time period, column $n$ is for the number of the order parameter of each subsystem. Then, the entropy $H_{j}$ for the order parameter $j$ for each subsystem is:

$$
H_{j}=-(1 / \ln t) \sum_{1}^{t} f_{i j} \ln \left(f_{i j}\right), \quad j=1,2, \cdots, n
$$

where $f_{i j}=\gamma_{i j} / \sum_{1}^{t} \gamma_{i j}$, and $f_{i j} \ln \left(f_{i j}\right)=0$ if $f_{i j}=0$. The lower the information entropy $H_{j}$, the larger the entropy weight $\omega_{j}$, which means that the contribution of the index to the evaluation results is greater. Thus, the entropy weight $\omega_{j}$ for the order parameter $j$ for each subsystem can be calculated as:

$$
\omega_{j}=\frac{1-H_{j}}{n-\sum_{j=1}^{n} H_{j}}, \quad 0 \leq \omega_{j} \leq 1, \quad \sum_{j=1}^{n} H_{j}=1
$$

It is assumed that, the order degrees of the each subsystem of the integrated MSW management synergy system are $u_{i}^{0}\left(X_{i}\right)$ at a given initial time $t_{0}$, and the order degree change to $u_{i}^{m}\left(X_{i}\right)$ at time $t_{m}$ as the system dynamically evolves. Then, the integrated MSW management synergy degree $\rho$ can be defined as follows:

$$
\rho=\theta\left\{\prod_{i=1}^{4}\left|u_{i}^{m}\left(X_{i}\right)-u_{i}^{0}\left(X_{i}\right)\right|\right\}^{1 / 4}
$$

$$
\theta=\frac{\min _{i}\left(u_{i}^{m}\left(X_{i}\right)-u_{i}^{0}\left(X_{i}\right) \neq 0\right)}{\left|\min _{i}\left(u_{i}^{m}\left(X_{i}\right)-u_{i}^{0}\left(X_{i}\right) \neq 0\right)\right|}
$$

From Equation (6), when the order degree of the four subsystems all increases from time $t_{0}$ to $t_{m}, \theta=1$, otherwise, $\theta=-1$. Therefore, the range of the synergy degree value is $\rho \in[1,1]$, The larger $\rho$ is, the higher the synergy degree of the urbanization system will be; on the contrary, the smaller $\rho$ is, the lower the synergy degree of urbanization system will be.

The integrated MSW management dynamic synergy degree $\rho_{d}$ can also be defined as follows:

$$
\rho_{d}=\theta\left\{\prod_{i=1}^{4}\left|u_{i}^{m}\left(X_{i}\right)-u_{i}^{m-1}\left(X_{i}\right)\right|\right\}^{1 / 4}
$$

\section{Data Resource}

The original data of this study are obtained from the "Harbin Statistical Yearbook" (2011-2020), the "China Urban Construction Statistical Yearbook" (2010-2019), and some of the order parameter data were collected from surveys of households, which were picked by both simple random sampling and stratified sampling procedures. Samples were selected from Nan-gang District, Dao-li District, Dao-wai District, Xiang-fang District and Ping-fang District. Five communities were sampled in each of these districts, and twenty families

\begin{tabular}{|c|c|c|c|c|c|c|c|c|c|c|c|}
\hline \multicolumn{2}{|l|}{ Year } & 2010 & 2011 & 2012 & 2013 & 2014 & 2015 & 2016 & 2017 & 2018 & 2019 \\
\hline \multirow{4}{*}{$\begin{array}{l}\text { MSW separation } \\
\text { subsystem }\left(X_{l}\right)\end{array}$} & $X_{11}$ & 2.77 & 2.88 & 3.00 & 3.04 & 3.14 & 3.29 & 3.44 & 3.57 & 3.65 & 3.63 \\
\hline & $X_{12}$ & 2.39 & 2.43 & 2.46 & 2.52 & 2.58 & 2.63 & 2.78 & 2.87 & 2.97 & 3.09 \\
\hline & $X_{13}$ & 2.34 & 2.64 & 3.25 & 3.40 & 3.57 & 3.72 & 3.89 & 4.34 & 4.67 & 4.64 \\
\hline & $X_{14}$ & 2.43 & 2.70 & 2.90 & 2.79 & 2.95 & 3.07 & 3.43 & 3.60 & 3.54 & 3.60 \\
\hline \multirow{4}{*}{$\begin{array}{l}\text { MSW collection } \\
\text { subsystem }\left(X_{2}\right)\end{array}$} & $X_{21}$ & 2.89 & 2.78 & 2.95 & 3.18 & 3.24 & 3.36 & 3.42 & 3.56 & 3.69 & 3.72 \\
\hline & $X_{22}$ & 15153 & 28720 & 34720 & 35220 & 32220 & 34220 & 36080 & 36235 & 36554 & 44220 \\
\hline & $X_{23}$ & 119.27 & 120.60 & 125.60 & 131.40 & 139.09 & 143.26 & 163 & 168.27 & 165.56 & 184.88 \\
\hline & $X_{24}$ & 4835 & 5720 & 6689 & 7125 & 7945 & 8255 & 8980 & 9410 & 8908 & 9676 \\
\hline \multirow{3}{*}{$\begin{array}{l}\text { MSW transporta- } \\
\text { tion } \\
\text { subsystem }\left(X_{3}\right)\end{array}$} & $X_{31}$ & 1020 & 1703 & 2172 & 2314 & 3011 & 3067 & 3118 & 3466 & 3486 & 3641 \\
\hline & $X_{32}$ & 2.04 & 2.37 & 2.52 & 2.69 & 2.81 & 3.03 & 3.11 & 3.26 & 3.35 & 3.37 \\
\hline & $X_{33}$ & 2.06 & 2.37 & 2.50 & 2.73 & 2.84 & 2.92 & 3.15 & 3.29 & 3.45 & 3.59 \\
\hline \multirow{4}{*}{$\begin{array}{l}\text { MSW disposal } \\
\text { subsystem }\left(X_{4}\right)\end{array}$} & $X_{41}$ & 98.89 & 96.15 & 107.14 & 114.70 & 118.22 & 131.26 & 149.63 & 153.71 & 151.79 & 184.88 \\
\hline & $X_{42}$ & 2.83 & 2.96 & 3.05 & 3.20 & 3.24 & 3.31 & 3.43 & 3.54 & 3.62 & 3.68 \\
\hline & $X_{43}$ & 2.08 & 2.45 & 2.79 & 3.20 & 3.34 & 3.41 & 3.63 & 3.76 & 3.87 & 3.94 \\
\hline & $X_{44}$ & 3.24 & 3.47 & 3.69 & 3.89 & 4.12 & 4.19 & 4.37 & 4.23 & 4.45 & 4.59 \\
\hline
\end{tabular}
in each community were issued questionnaires. Five groups of students in Harbin Engineering University participated in the research survey during November

Table 2. Order parameters original data. 
12-28, 2019. Respondents were asked to score the performance of the order parameter using the 1 to 5 rating scale (poor to excellent) by year. In the end, 428 out of the 500 sampled households were surveyed in this study, yielding $85.60 \%$ response rate. And the integrated MSW management order parameter original data is shown in Table 2.

\section{Results and Discussion}

\section{MSW Separation Subsystem}

According to the interactive relationship of the five order parameters of the MSW separation subsystem from 2010 to 2019, Fig. 2 showed that the order curve was on a rising trend. The rate of the rise dramatically increased over the years, and the order degree reached a maximum of 0.9918 in 2019.

Considering the interactive relationship of the five order parameters, the publicity and education $\left(X_{11}\right)$ made the most significance on the performance of MSW separation subsystem from 2011 to 2015. The main reason for this contribution was the remarkable fact that Heilongjiang People's Government [37] proposed that the publicity and education on MSW separation should be strengthen during the " $12^{\text {th }}$ FiveYear Plan" period (2011-2015). Besides, “China's 12 ${ }^{\text {th }}$ Five-Year Plan on Facility Construction of Municipal Solid Waste Harmless Disposal" [38] proposed that it was necessary to mobilize the people's initiative of participating in the MSW management. And with the well-publicized of the MSW separation knowledge, the environmental-friendly spirit of public had been cultivated over the years, then the public were willing to participate in the MSW separation actively. And then China's " $13^{\text {th }}$ Five-Year Plan" made it clear that to guide the residents to consciously carry out the classification of MSW [39]. Hence, the public participation $\left(X_{12}\right)$ affected the most during the following period 20162019. Aware of the severity of environmental impacts from MSW management, the central and local Chinese governments have been developing strategical and tactical policies, laws and regulations, to improve the environmental performances of the MSW management systems. Moreover, the intensive implementation of relative mandatory policies and regulation $\left(X_{13}\right)$ also had the significant effect on the performance of MSW separation subsystem. Government had been trying to implement more environmentally friendly MSW management mechanisms, instead of the dumping, persuading the public to sort their own MSW. It was a foundational step for improving the MSW separation system.

\section{MSW Collection Subsystem}

Fig. 3 showed that the synergetic development of MSW collection subsystem from 2010 to 2019 was in a good and orderly state and the order curve was on a rising trend. The rate of the rise fluctuated but gradually increased from 2010 to 2019, and the order degree reached a maximum of 1.0000 in 2019.

According to the mutual effect of the four order parameters, number of MSW containers $\left(X_{22}\right)$ in Harbin was the greatest distributor to MSW collection

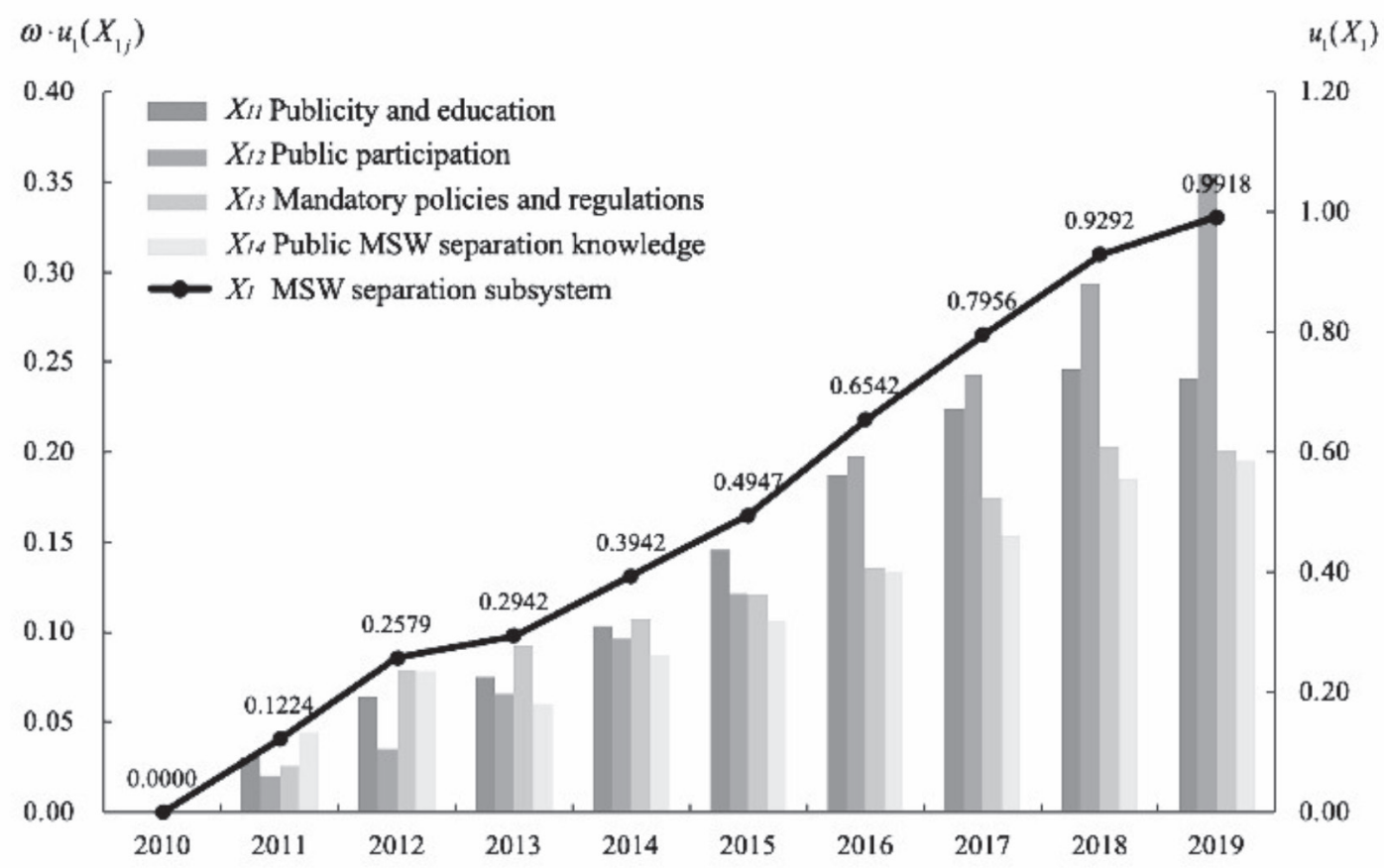

Fig. 2. Order degree dynamic development for MSW separation subsystem and order parameters. 


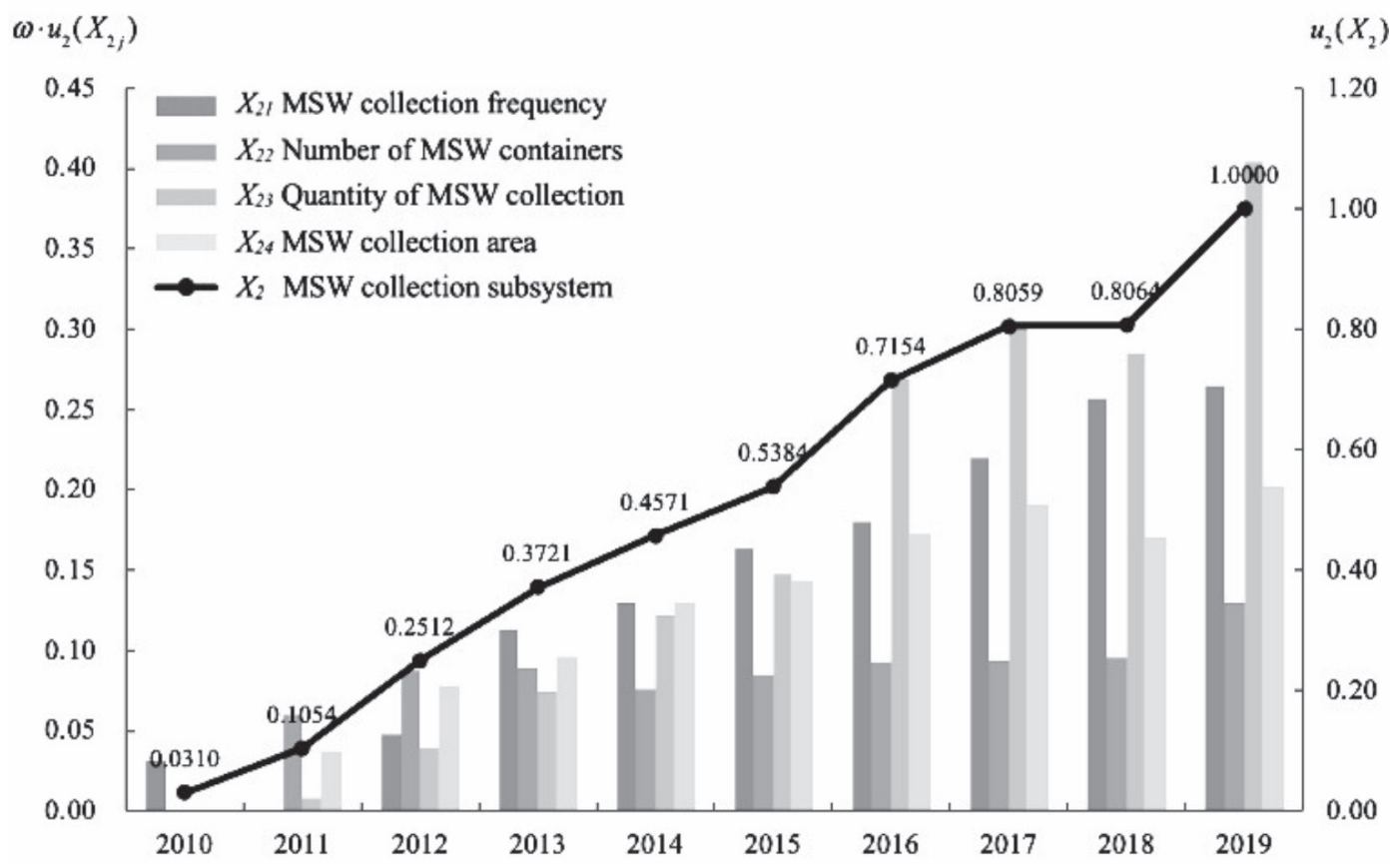

Fig. 3. Order degree dynamic development for MSW collection subsystem and order parameters.

subsystem from 2011 to 2012. It indicated that Harbin increased the MSW containers at the beginning of " $12^{\text {th }}$ Five-Year Plan" period according to the demands of making proper allocation of MSW collection bags and containers by the China's National Development and Reform Commission and China's Ministry of Housing and Urban-Rural Development [38]. Moreover, MSW is easy to be frozen in winter due to the unique cold weather and low temperature in Harbin, which will increase the difficulty and burdens of MSW collection. Furthermore, MSW collection is required to be reliability and accuracy in time in Harbin to decrease environmental pollutions when MSW was piled up for a long time. So, MSW collection frequency $\left(X_{21}\right)$ was the important factor on MSW collection subsystem during the period of 2014-2016. Quantity of MSW collection $\left(X_{23}\right)$ had the greatest effect on the performance of MSW separation subsystem from 2016 to 2019. The main

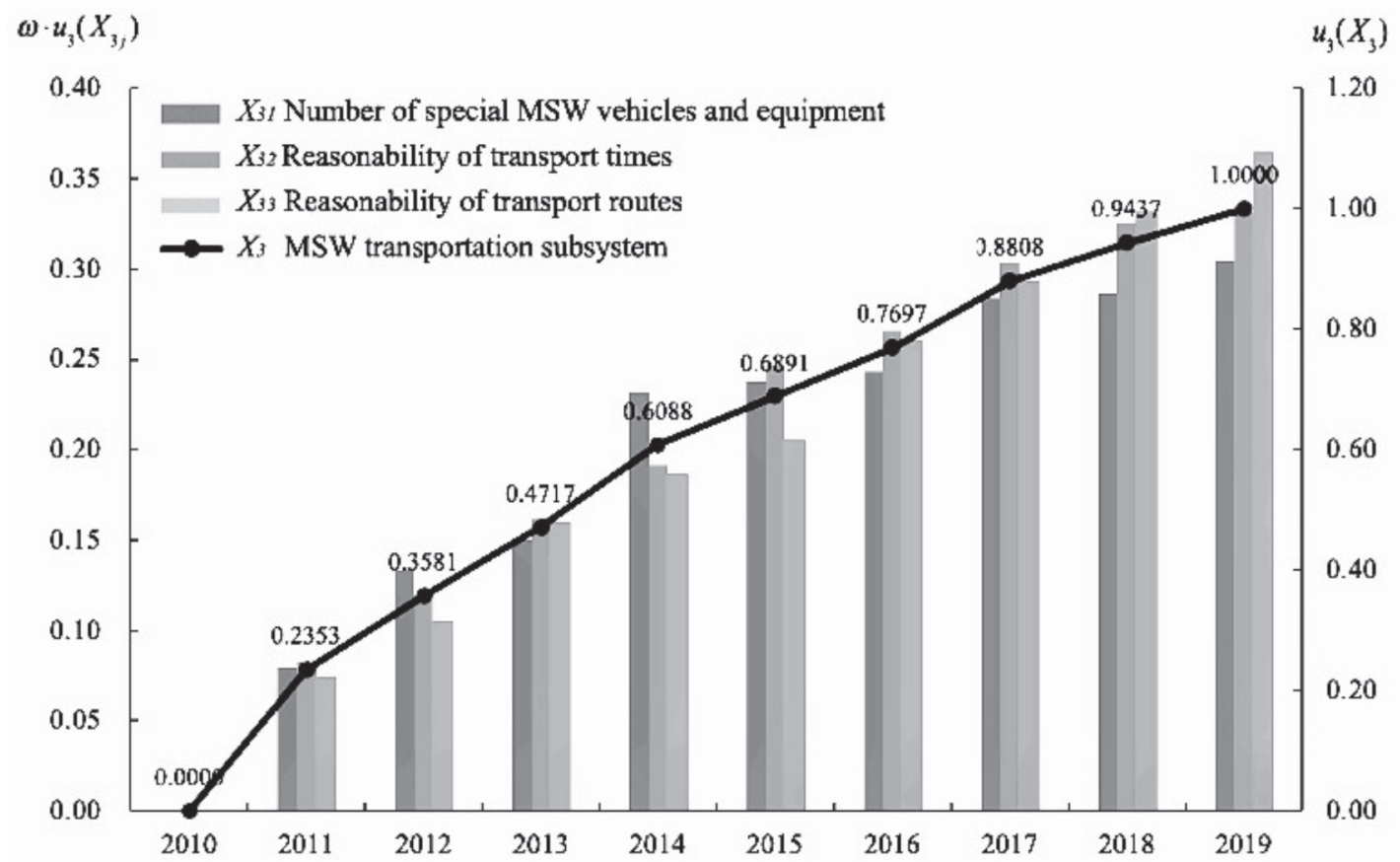

Fig. 4. Order degree dynamic development for MSW transportation subsystem and order parameters. 
reason was that the MSW collection quantity reflected the performance of the MSW collection process, and it would directly affect the people's living environment. "China's $13^{\text {th }}$ Five-Year Plan on Facility Construction of Municipal Solid Waste Harmless Disposal” proposed that the municipalities should call for a high rate and high efficiency of MSW collection. Harbin was required to enhance the MSW collection and increase the collection quantity.

\section{MSW Transportation Subsystem}

Fig. 4 showed that the synergetic development of the order degrees of MSW transportation subsystem from 2010 to 2019 was in a good state with a high order degree. The order curve was on a rising trend, and the order degree reached a maximum of 1.0000 in 2019.

Considering the mutual effect of the three order parameters, number of MSW vehicles and equipment $\left(X_{31}\right)$ greatly promoted the rise of the order degree of the MSW transportation subsystem during the period 20112015. This is because Harbin made overall planning for MSW transport stations coordination and management during the " $12^{\text {th }}$ Five-Year Plan" period (2011-2015), and more compression MSW vehicles and equipment had been constructed and upgraded as required by “China's $12^{\text {th }}$ Five-Year Plan on Facility Construction of Municipal Solid Waste Harmless Disposal" [38]. Besides, reasonability of transport times $\left(X_{32}\right)$ and transport routes $\left(X_{33}\right)$ were the important factors on MSW transportation subsystem during the period of 2016-2019. "China's 13 $13^{\text {th }}$ Five-Year Plan on Facility Construction of Municipal Solid Waste Harmless
Disposal" [39] further proposed that it was necessary to optimize the MSW transport routes and transport times. MSW usually get transported at night and implement off-peak operation with other social vehicles according to the traffic conditions in Harbin. Harbin also optimized the MSW transport routes reasonably according to the MSW collection quantity and transport distance to achieve the goal of high efficiency with reasonable costs, which promoted the synergetic evolution of the MSW transportation subsystem to a certain extent.

\section{MSW Disposal Subsystem}

Fig. 5 showed the order curve of MSW disposal subsystem was in a continuously rising trend since 2010, and the order degree reached a maximum of 1.0000 in 2019.

Considering the correlation of the four order parameters, MSW disposal technology $\left(X_{42}\right)$ was the important factor on MSW disposal subsystem during the period of 2011-2014. Heilongjiang People's Government [37] have made it a policy mandate to enhance and improve the MSW disposal technology, also demanded a drastic change in the MSW disposal method, vigorously urging to decrease the use of landfill and increase the use of incineration. At the same time, MSW disposal technology was required to be upgraded to support MSW disposal since 2015. Hence, it is indicated that quantity of MSW disposal $\left(X_{41}\right)$ had the greatest effect on the performance of MSW disposal subsystem since 2015 was mainly attributed to the rise of the evaluation standards. "The Heilongjiang's $12^{\text {th }}$ Five-Year Plan for

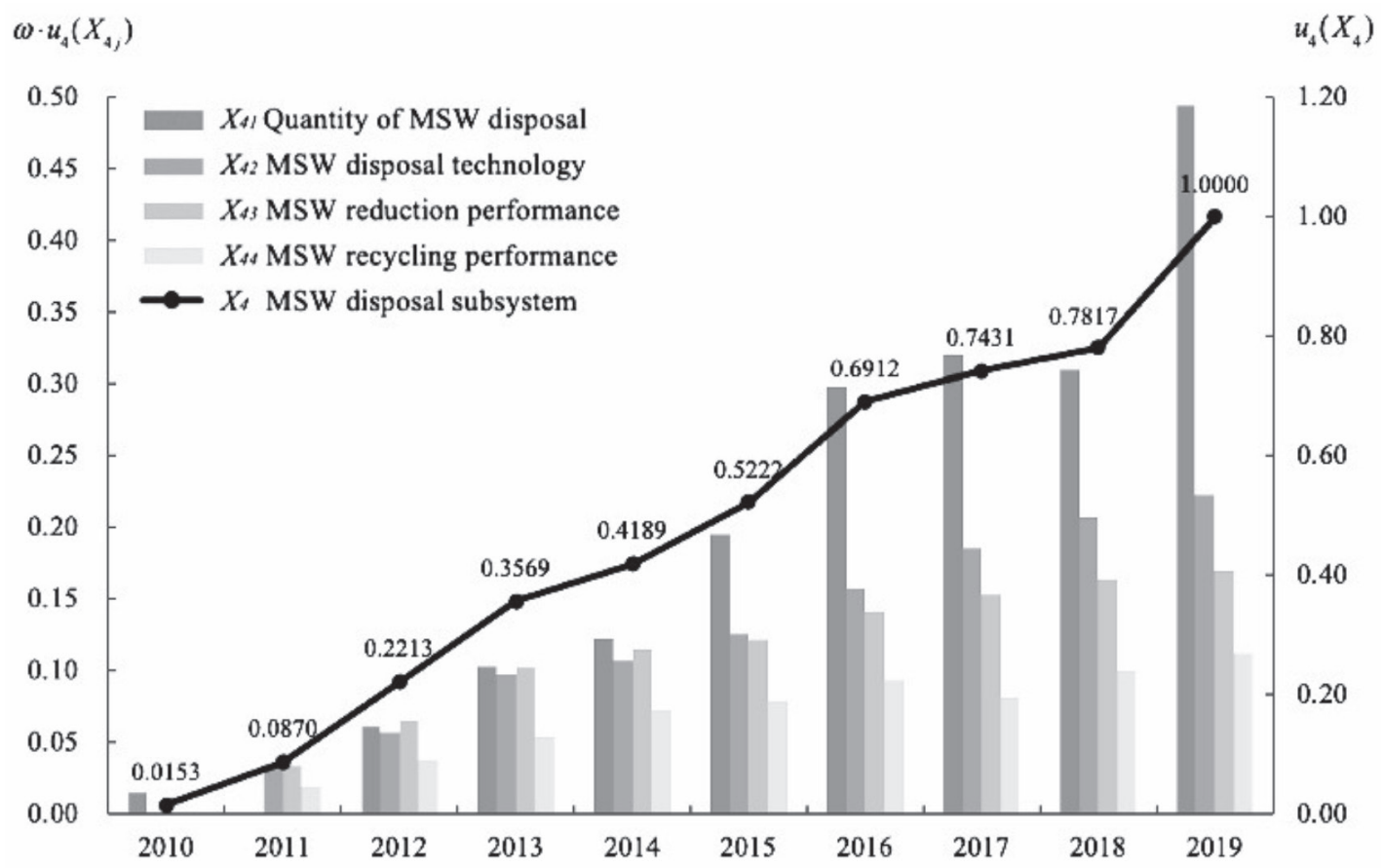

Fig. 5. Order degree dynamic development for MSW disposal subsystem and order parameters. 
Table 3. Synergy degree of integrated MSW management synergy system.

\begin{tabular}{|c|c|c|c|c|c|c|c|c|c|}
\hline & 2011 & 2012 & 2013 & 2014 & 2015 & 2016 & 2017 & 2018 & 2019 \\
\hline$\rho$ & 0.1139 & 0.2571 & 0.3591 & 0.4552 & 0.5478 & 0.6930 & 0.7979 & 0.8522 & 0.9866 \\
\hline$\rho_{\mathrm{d}}$ & 0.1139 & 0.1348 & 0.0909 & 0.0949 & 0.0899 & 0.1356 & 0.1023 & 0.0191 & 0.1094 \\
\hline
\end{tabular}

Environmental Protection" [40] implemented an MSW disposal system and reached a disposal rate of at least $85 \%$ by 2015 in Harbin. During the " $13^{\text {th }}$ Five-Year Plan" period, MSW disposal rate was raised to reach $93 \%$ by 2020 [41]. This policy intervention resulted in a drastic increase in the performance of MSW disposal from 2015 to 2019. Harbin enhanced the level of its MSW disposal capacity, promoting this subsystem to realize the evolution of synergetic self-organization.

\section{Integrated MSW Management Synergy System}

According to Equations (5)-(7), the changes of synergy degree of the integrated MSW management synergy system from 2011 to 2019 can be obtained in Table 3. In order to reflect the cooperative evolutionary trend of each subsystem and the overall system more intuitively, the development trend is presented in Fig. 6 .

As can be seen from Table 3 and Fig. 6, in 2011-2017, the synergy degree of the integrated MSW management synergy system showed an upward shock, and the order degrees of all the subsystems increased to varying degrees, indicating that the four subsystems have the ability for self-organization. Besides, the value of the dynamic synergy degree of the integrated MSW management synergy system was positive and steady, showing that the synergy system of integrated MSW management developed to an ordered state as a whole. From a dynamic point of view (with the base period being one year ahead of each year), the order degrees of all the subsystems every year were larger than the previous year after 2010, leading to the positive value of synergy degree from 2011 to 2019. Over this period, the MSW transportation subsystem order degree was relatively higher than the others, and the order degree of the MSW separation subsystem was the lowest.

During the " $12^{\text {th }}$ Five-Year Plan" period, it was noticed that the MSW transportation subsystem $\left(X_{3}\right)$ was the highest level among all the subsystems, indicating that significant concerns have been raised regarding the improvement of MSW transportation network in Harbin. MSW transportation had been always imposed

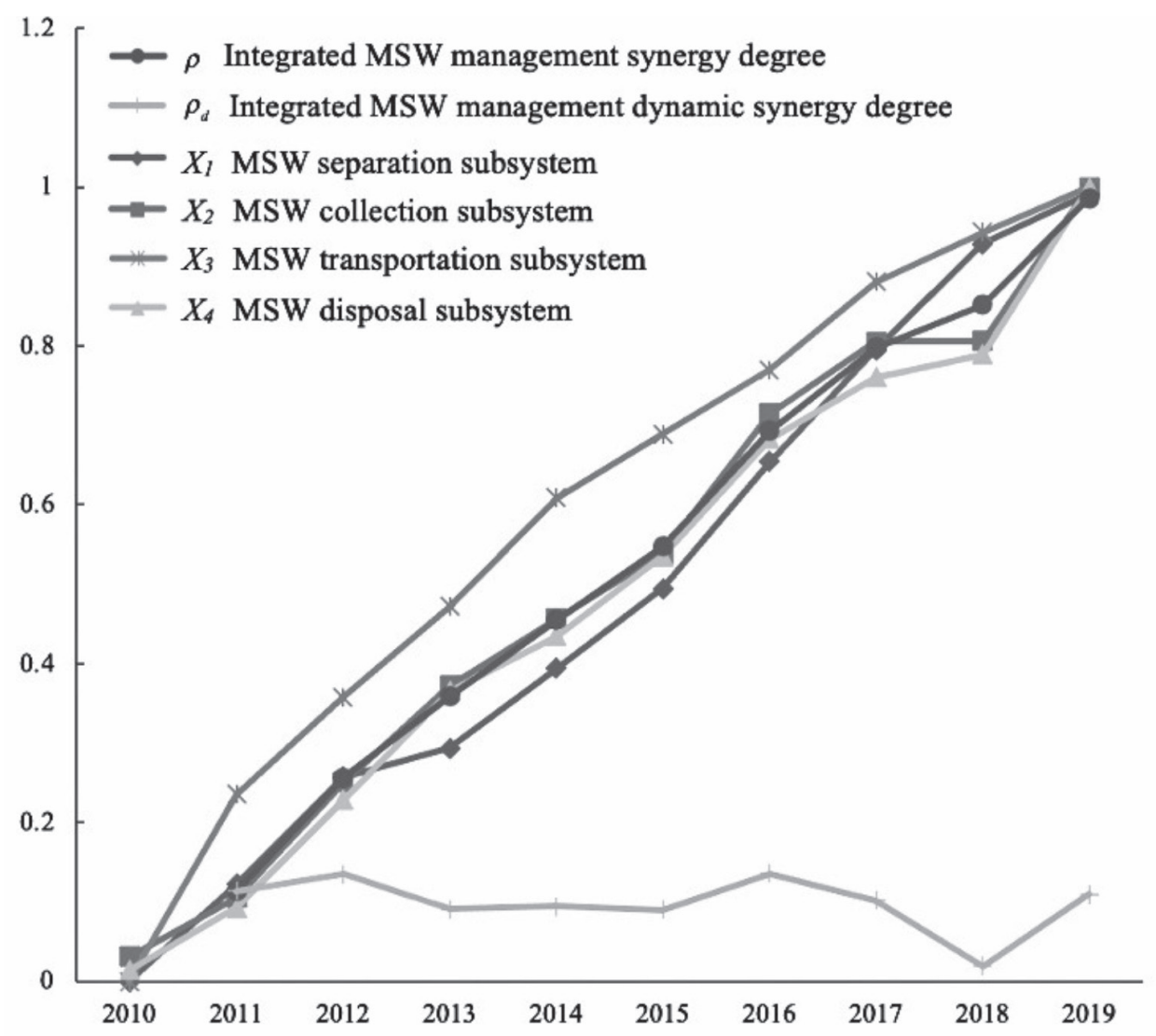

Fig. 6. Dynamic development of synergetic degree of system and subsystems. 
more demanding standards in Harbin due to its high latitude and severe cold climate in winter. Meanwhile, Heilongjiang People's Government [40] proclaimed to improve the MSW transportation networks and established the professionalize environmentally friendly and efficient MSW collection and transportation system. Harbin had upgraded the existing facilities for MSW transportation, promoted compressed transportation equipment to avoid the spills and dirty during transportation. Additionally, the order degree of the MSW separation subsystem $\left(X_{1}\right)$ was the lowest before 2016, however it had been greatly accelerated in 2017, indicating that some achievements have been made in the MSW separation. Heilongjiang People's Government [41] required Harbin to propose an MSW separation scheme according to the actual situation, and gradually promote the MSW collection to contribute a coordinated and efficient MSW collection system. In March 2017, the China's National Development and Reform Commission and China's Ministry of Housing and Urban-Rural Development [42] issued a plan for improving the MSW separation system, proposing new legislation and standards for MSW separation by 2020. Moreover, compared with the other subsystems, it is noticed that there was a remarkably increase in MSW disposal subsystem $(X)$ and MSW collection subsystem $\left(X_{2}\right)$ especially from 2016-2019, indicating that more attention had been paid to them during the " $13^{\text {th }}$ FiveYear Plan" period. Heilongjiang People's Government [41] had given priority to MSW disposal facilities investment, and local government should increase the financial support to extend MSW collection coverage for centralized MSW disposal. MSW separation, collection and disposal had been gradually promoted since 2016, and the quality of the MSW management has been increasingly improved in Harbin.

\section{Conclusions}

Integrated municipal solid waste (MSW) management synergy system is a multi-dimensional, multi-structured, complex system that is affected by many factors. This paper developed an integrated MSW management synergy system consisting of four subsystems: MSW separation subsystem, MSW collection subsystem, MSW transportation subsystem, and MSW disposal subsystem from the perspective of whole life cycle theory. Harbin, China was chosen as the study area due to its distinct cold weather makes MSW management faces more challenges. The synergy degree model was used to analyze the order degree value changes of the four subsystems and the synergy degree value changes of the synergy system, so as to scientifically reflect the systematic characteristics and development status in the process of MSW management, and then further determine the vulnerable part of the integrated MSW management process. The results showed that the order degree of the MSW transportation subsystem of integrated MSW management synergy system in the study area improved continuously. Meanwhile, the order degree of the MSW separation subsystem developed slowly, staying at a relatively low level overall. As a higher synergy degree indicates higher efficiency, measures and policies should be formulated to focus on the MSW separation to keep pace with the integrated MSW management trends in Harbin.

\section{Acknowledgments}

This work was supported by the [Major Project of Philosophy and Social Sciences Research, Ministry of Education] under Grant [number 17JZD026]; [National key research and development plan key special project] under Grant [number 2018YFC1903605]; [Fundamental Research Funds for the Central Universities] under Grant [number GK2090260158]; [the PhD Student Research and Innovation Fund of the Fundamental Research Funds for the Central Universities] under Grant [number HEUGIP201719]; [Training Program in Response to Major National Strategic Needs - Think Tanks] under Grant [number HEUCFP201823 and HEUCFP201834]; [The Leading Research Project of Shanghai Jiao Tong University - Think Tanks] under Grant [number ZXYJ-2020017].

\section{Conflict of Interest}

The authors declare no conflict of interest.

\section{References}

1. HASSAN M., WANG X., WANG F., WU D., HUSSAIN A., XIE B. Coupling ARB-based biological and photochemical (UV/TiO 2 and $\mathrm{UV} / \mathrm{S}_{2} \mathrm{O}^{2-}$ ) techniques to deal with sanitary landfill leachate. Waste Management, 63, 292, 2016.

2. KHARAT M.G., MURTHY S., KAMBLE S.J., RAUT R.D., KAMBLE S.S., KHARAT M.G. Fuzzy multicriteria decision analysis for environmentally conscious solid waste treatment and disposal technology selection. Technology in Society, 57, 20, 2019.

3. YUAN X.L., FAN X.H., LIANG J.X., LIU M.Y., TENG Y.Q., MA Q., WANG Q.S., MU R.M., ZUO J. Public perception towards waste-to energy as a waste management strategy: A case from Shandong, China. International Journal of Environemtal Research and Public Health, 16 (16), 2997, 2019.

4. CHINA'S MINISTRY OF HOUSING AND URBANRURAL DEVELOPMENT. China Urban Construction Statistical Yearbook 2019; China Statistics Press: Beijing, China, 2020 [In Chinese].

5. LEE C.K.M.,YEUNG C.L., XIONG Z.R., CHUNG S.H. A mathematical model for municipal solid waste management - A case study in Hong Kong. Waste Management, 58, 430, 2016. 
6. CHU Z.J., WANG W.N., ZHOU A., HUANG W.C. Charging for municipal solid waste disposal in Beijing. Waste Management, 94, 85, 2019.

7. ASEFI H., LIM S. A novel multi-dimensional modeling approach to integrated municipal solid waste management. Journal of Cleaner Production, 166, 1131, 2017.

8. MOHAMMADI M., JÄMSÄ-JOUNELA S.L., HARJUNKOSKI I. Optimal planning of municipal solid waste management systems in an integrated supply chain network. Computers \& Chemical Engineering, 123, 155, 2019.

9. MARSHALL R.E., FARAHBAKHSH K. Systems approaches to integrated solid waste management in developing countries. Waste Management, 33 (4), 988, 2013.

10. SHARHOLY M., AHMAD K., MAHMOOD G., TRIVEDI R. Municipal solid waste management in Indian cities - A review. Waste Management, 28, 459, 2008.

11. GUERRERO L.A., MAAS G., HOGLAND W. Solid waste management challenges for cities in developing countries. Waste Management, 33 (1), 220, 2013.

12. TAN S.T., LEE C.T., HASHIM H., HO W.S., LIM J.S. Optimal process network for municipal solid waste management in Iskandar Malaysia. Journal of Cleaner Production, 71, 48, 2014.

13. FERNANDO R.L.S. Solid waste management of local governments in the Western Province of Sri Lanka: An implementation analysis. Waste Management, 84, 194, 2019.

14. ZAMAN A.U. Identification of key assessment indicators of the zero waste management systems. Ecological indicators, 36, 682, 2014.

15. PAES M.X., DE MEDEIROS G.A., MANCINI S.D., BORTOLETO A.P., PUPPIM DE OLIVEIRA J.A., KULAY L.A. Municipal solid waste management: Integrated analysis of environmental and economic indicators based on life cycle assessment. Journal of Cleaner Production, 254, 119848, 2020.

16. DAS S., LEE S.H., KUMAR P., KIM K.H., LEE S.S., BHATTACHARYA S.S. Solid waste management: scope and the challenge of sustainability. Journal of Cleaner Production, 228, 658, 2019.

17. YAY A.S.E. Application of life cycle assessment (LCA) for municipal solid waste management: a case study of Sakarya. Journal of Cleaner Production, 94, 284, 2015.

18. RIGAMONTI L., GROSSO M., GIUGLIANO M. Life cycle assessment of sub-units composing a MSW management system. Journal of Cleaner Production, 18, $1652,2010$.

19. COELHO L.M.G., LANGE L.C., COELHO H.M.G. Multicriteria decision making to support waste management: A critical review of current practices and methods. Waste Management \& Research, 35 (1), 3, 2017.

20. PAREKH H., YADAV K., YADAV S., SHAH N. Identification and assigning weight of indicator influencing performance of municipal solid waste management using AHP. Ksce Journal Of Civil Engineering, 19 (1), 36, 2015.

21. HARIJANI A.M., MANSOUR S., KARIMI B. A multiobjective model for sustainable recycling of municipal solid waste. Waste Management \& Research, 35 (4), 387399, 2017.

22. SU J.P., HUNG M.L., CHAO C.W., MA H.W. Applying multi-criteria decision-making to improve the waste reduction policy in Taiwan. Waste Management \& Research, 28 (1), 20, 2010.
23. PAUL K., CHATTOPADHYAY S., DUTTA A., KRISHNA A., RAY S. A comprehensive optimization model for integrated solid waste management system: A case study. Environmental Engineering Research, 24 (2), 220, 2019.

24. ARIKAN E., SIMȘIT-KALENDER Z.T., VAYVAY Ö. Solid waste disposal methodology selection using multicriteria decision making methods and an application in Turkey. Journal of Cleaner Production, 42 (20), 403, 2017.

25. ASEFI H. LIM S. A novel multi-dimensional modeling approach to integrated municipal solid waste management. Journal of Cleaner Production, 166 (10), 1131, 2017.

26. DONG Y.H., AN A.K., YAN Y.S., YI S. Hong Kong's greenhouse gas emissions from the waste sector and its projected changes by integrated waste management facilities. Journal of Cleaner Production, 149, 690, 2017.

27. PHONPHOTON N. PHARINO C. A system dynamics modeling to evaluate flooding impacts on municipal solid waste management services. Waste Management, 87, 525, 2019.

28. FAGNANI E. GUIMARÃES J.R. Waste management plan for higher education institutions in developing countries: The continuous improvement cycle model. Journal of Cleaner Production, 147 (20), 108, 2017.

29. MALAKAHMAD A., NASIR M.Z.Z.C.M, KUTTY S.R.M., ISA, M.H. Solid waste characterization and recycling potential for University Technology PETRONAS academic buildings. American Journal of Environmental Sciences, 6 (5), 422, 2010.

30. TSAI F.M., BUI T., TSENG M., LIM M.K. HU J. Municipal solid waste management in a circular economy: A data-driven bibliometric analysis. Journal of Cleaner Production, 275, 124, 2020.

31. MARSHALL R.E. FARAHBAKHSH K. Systems approaches to integrated solid waste management in developing countries. Waste Management, 33 (4), 988, 2013.

32. SOLTANI A., HEWAGE K., REZA B., SADIQ, R. Multiple stakeholders in multi-criteria decision-making in the context of municipal solid waste management: A review. Waste Management, 35, 318, 2015.

33. MENIKPURA S.N.M., SANG-ARUN J., BENGTSSON M. Integrated solid waste management: an approach for enhancing climate co-benefits through resource recovery. Journal of Cleaner Production, 58, 34, 2013.

34. OTHMAN S.N., ZAINON NOOR Z., ABBA A.H., YUSUF R.O., ABU HASSAN M.A. Review on life cycle assessment of integrated solid waste management in some Asian countries. Journal of Cleaner Production, 41, 251, 2013.

35. WANG Z., XUE Q., JI Y., YU Z. Indoor environment quality in a low-energy residential building in winter in Harbin. Building and Environment, 135, 194, 2018.

36. WU H., TAO F., YANG B. Optimization of vehicle routing for waste collection and transportation. International Journal of Environmental Research and Public Health, 17 (14), 4963, 2020.

37. HEILONGJIANG PEOPLE'S GOVERNMENT. Implementation Opinions for the Heilongjiang Province on Further Strengthening the Municipal Solid Waste Disposal. 2012 [In Chinese].

38. CHINA'S NATIONAL DEVELOPMENT AND REFORM COMMISSION, CHINA'S MINISTRY OF HOUSING AND URBAN-RURAL DEVELOPMENT. The China's $12^{\text {th }}$ Five-Year Plan on Facility Construction of Municipal Solid Waste Harmless Disposal. 2012 [In Chinese]. 
39. CHINA'S NATIONAL DEVELOPMENT AND REFORM COMMISSION, CHINA'S MINISTRY OF HOUSING AND URBAN-RURAL DEVELOPMENT. The China's $13^{\text {th }}$ Five-Year Plan on Facility Construction of Municipal Solid Waste Harmless Disposal. 2016 [In Chinese].

40. HEILONGJIANG PEOPLE'S GOVERNMENT. The Heilongjiang's $12^{\text {th }}$ Five-Year Plan for Environmental Protection. 2012 [In Chinese].
41. HEILONGJIANG PEOPLE'S GOVERNMENT. The Heilongjiang's $13^{\text {th }}$ Five-Year Plan for Environmental Protection. 2016 [In Chinese]

42. CHINA'S NATIONAL DEVELOPMENT AND REFORM COMMISSION, CHINA'S MINISTRY OF HOUSING AND URBAN-RURAL DEVELOPMENT. Implementation Plan for Municipal Solid Waste Separation System. 2017 [In Chinese]. 